\title{
Oxygen Analyzer Device
}

National Cancer Institute

\section{Source}

National Cancer Institute. Oxygen Analyzer Device. NCI Thesaurus. Code C50094.

A device designed to measure the concentration of oxygen in a gas mixture. 